\title{
Insights into tourism demand and tourism behavior: Four papers using multiple perspectives and structural equation modeling
}

\author{
Guy Assaker ${ }^{1}$
}

Received: 28/07/2011

\begin{abstract}
1 Research Fellow, Centre For Tourism and Leisure Studies, School of Management, University of South Australia, phone: +61 8830 20425, e-mail: guy.assaker@unisa.edu.au
\end{abstract}

Supervisor: Professor Peter O'Connor, ESSEC Business School (France)

Professor Vincenzo Esposito Vinzi, ESSEC Business School (France)

Institution awarding the Ph. D. Degree: ESSEC Business School, France

Date of defence: $1^{\text {st }}$ July 2010

(C) 2011 International University College. All rights reserved

Citation: Assaker, G. (2011), Insights into tourism demand and tourism behavior: Four papers using multiple perspectives and structural equation modeling. Doctoral dissertation summary. European Journal of Tourism Research 4(2), pp. 237-241

\section{Goal and objectives of the dissertation}

This work explores a significant issue in tourism - namely, tourism demand at a destination - as far as both academic research and tourism practice are concerned. The complexity of this issue demands multipleperspective research based on scientific research methodologies. This study seeks to address this need by employing the structural equation modelling (SEM) approach to further examine tourism demand from both tourism development and tourist behaviour perspectives.

Chapter 1 aims to identify the best practices when applying SEM in order to develop appropriate guidelines that are subsequently used to test the various proposed tourism demand models. Chapter 2 aims to advance the field's knowledge regarding the relationship between supply side variables used in tourismbased studies by extending existing tourism demand models to include additional factors namely, environment and society variables. The chapter examines whether and how economic, infrastructural, social, and environmental variables impact tourists' inflow into a specific destination at country aggregate levels. Chapter 3 extends the analysis from Chapter 2, examining whether the causal relationships defined in Chapter 2 hold true across both developed and less developed countries equally. Finally, Chapter 4 further advances the literature on tourists behaviour (as opposed to aggregate demand level) by examining which customer-level factors (and to what degree) affect tourists" immediate and future intentions to return to the destination. Thus, this study makes significant contributions to existing tourism literature.

\section{Methodology}

The present work applies different types of existing SEM models (e.g., traditional SEM with 
reflective constructs, multi-group constrained models, and latent growth curve models) to operationalize a variety of variables used in tourism demand forecasting. These models can also depict causal relationships among these variables to generate further results in tourism studies and advance theoretical development in tourism demand modeling at both the aggregate and individual (tourist behavior) levels.

Chapter 2 uses AMOS 16.0 to test causal hypotheses between supply-side factors and tourism construct by means of traditional SEM model with reflective constructs using a crosssectional data sample collected from a Euro monitor for 162 countries, for the year period 2004. Data from 2004 are used, as this dataset has fewer missing values compared to data available for 2005 onward. Chapter 3 uses advanced multigroup analysis sampling in AMOS 16.0 to test the same model across two groups of countries (developed vs. lessdeveloped countries) with the same dataset collected previously for the 162 countries for 2004.

Finally, Chapter 4 uses advanced LatentGrowth sampling in AMOS 16.0 to validate the proposed model on the effects of noveltyseeking, destination image, and overall satisfaction levels across intent to revisit trajectories, using data collected online in February 2009, among French, English, and German travelers, who flew for more than two hours to visit a sun-and-sand destination during the past six months.

\section{Results}

Research results and findings from this work are specific to each chapter, and they help enhance both researchers' and practitioners' comprehension of the phenomena of tourism demand.

In particular, results from Chapter 1 indicate that the use of SEM is still limited among tourism demand modeling, as only 21 studies were found to have used SEM in the past 12 years. Results also indicated that SEM techniques were applied inappropriately. Issues included the following: (1) the majority of 238 authors failed to specify how they handled the issue of missing data; (2) few papers discussed data distribution (normality), although all used traditional estimation methods to fit the model, which assumes dataset normality; (3) all papers could use alternative fit indices to further support overall model fit; (4) only half of the studies tested for reliability and validity of individual constructs, even though not doing so could lead to specification errors; (5) most of the authors re-specified their model without providing a theoretical justification; and (6) few studies provided enough detail to permit the work to be replicated. Thus, Chapter 1 demonstrates that both the application of SEM and presentation of results exhibit room for improvement.

Chapter 2 validates a structural equation model to capture the causal relationships between several dimensions of the destination paradigm - namely, the economy, society, and the natural and infrastructural environments. The findings confirmed the indirect, positive impact of economy on tourism through the infrastructure and environment constructs, while the direct relationship between the economy and tourism was non-significant. Furthermore, the infrastructure construct was posited to parallel the state of the society and was measured according to the level of technological advancement, access to the transportation infrastructure, and access to sanitation. The findings also confirm that infrastructure and environment have a direct, positive impact on generating tourism inflows.

Extending this analysis, Chapter 3 demonstrates that the a priori validated model did not replicate across both groups, making comparisons impossible. In investigating the individual results for each group, however, this chapter reveals that the composition of the economy construct differs across the two samples, and an altered relationship exists between the economy and infrastructure across both groups. A reduced model limited to infrastructure, environment, and tourism constructs has been found to fit both samples reasonably. Testing of the reduced model reveals that path coefficients were equal across groups. This means that the impact of 
destination factors (i.e., infrastructure and environment) both on each other and on tourism itself is the same across groups.

Finally, Chapter 4 explores the individual differences in re-visiting choice over time, in contrast to the previous two chapters, which follow a supply-side perspective to analyze tourism demand. Findings indicate that noveltyseeking behavior and low satisfaction among travelers have a negative impact on immediate intent to return, while a positive image of the destination has an indirect positive impact, through satisfaction, on immediate returns and a direct positive impact on future intentions to return. As such, destination image should be regarded a critical way to generate future revisits - even if a traveler was dissatisfied or had a poor experience.

\section{Theoretical conclusions}

Given the importance of tourism demand and thus tourism revenues in enhancing the economic prosperity of destinations worldwide, this work aims to extend the findings of tourist demand from several perspectives, at both aggregate and individual levels. It uses powerful statistical techniques, some of which are still underemployed and others not previously used in tourism literature, to validate existing theories and reveal new ideas.

In particular, Chapter 1 contributes by emphasizing how SEM (which has been previously underemployed due to its complexity) can suitably model tourist demand under various perspectives at both the aggregate and individual levels. While the importance and appeal of SEM for advancing research has been highlighted in other areas (Brannick, 1995; Chin, 1998; Shook, Ketchen, Hult, \& Kacmar, 2004), to date, no study has systematically assessed how SEM is used in tourism demand studies. Hence, this paper aims to assess the methodological quality of published studies and how they conform to statistical assumptions to validly use such techniques.

The contribution of the second chapter is that it investigates the dimensionality of the main constituents of the destination supply paradigm (namely, environment and society variables) to reveal how well each variable explains its underlying construct. By integrating several supply-side factors related to the destination, Chapter 2 provides more comprehensive results compared to previous applications of SEM that used a limited number of destination variables and subsequently provided only limited results (Turner, Reisinger, \& Witt, 1998; Turner \& Witt, 2001; Chathoth, 2001; Mazanec, Wober, \& Zins, 2007).

Chapter 3 further contributes to the overall understanding of tourism demand forecasting by extending causal relationships among factors applicable to a destination in general and to the specific extent of the country's economic development in particular. Such extension of results can provide substantial value for policymakers in both developed and less-developed parts of the world. Moreover, Chapter 3 provides insight into a technique for testing model invariance across multiple groups. Such applications are absent in the existing tourism literature.

Finally, Chapter 4 contributes by examining a tourist's intent to revisit a destination from a perspective of time. This information could be useful for understanding the appropriate time intervals for returns and the corresponding return likelihoods for visitors who have previously visited the destination. Despite several studies on repeat visit intention, few researchers have addressed the issue of repeat visit patterns (Feng and Jang, 2007). Thus, this paper fills a significant gap present in the literature.

\section{Practical application of the dissertation}

Together, these papers' findings help enhance readers' comprehension of tourism demand forecasting and provide insights to practitioners into factors they can use to drive tourism to their destinations. In particular, Chapter 1 demonstrates that room for improvement exists in both applying SEM and presenting results. To assist in this process, a checklist of issues was developed to be considered by both researchers and practitioners who are interested in forecasting tourism demand to 
Insights into tourism demand and tourism behavior: Four papers using multiple perspectives and structural equation modeling. Doctoral dissertation summary.

their destinations and who plan to use SEM as a primary tool for forecasting tourism demand.

The results from Chapter 2 should help policymakers understand how individual variables affect the economy, society, and tourism industry aggregately and thus provide destination managers with a comprehensive framework to help them understand what actions or investments will help develop a country's tourism industry effectively. Chapter 3 further discriminates between those previously identified actions for policymakers across both developed and less-developed parts of the world.

Finally, Chapter 4's results provide more comprehensive implications for destination managers and marketers. Tourists have many options to satisfy their travel needs in today's world; thus, it is important for destinations to examine tourists' intent to revisit in addition to their actual visits. It is also important to understand what factors are responsible for both immediate and deferred visits. Examining the intent to revisit a destination from a time perspective is thus helpful for both theoretical and practical reasons.

\section{Content of the dissertation}

Abstract of chapter one

Title: Structural Equation Modeling in Tourism Demand Forecasting: A Critical Review

The first chapter reviews prior applications of structural equation modelling to tourism demand forecasting in seven prominent tourism and service journals (Journal of Travel Research, Tourism Management, Tourism Economics, Annals of Tourism Research, Journal of Hospitality and Tourism Research, Journal of Service Research, and Journal of Services Research) over a 12-year period (1998 to 2009). Having identified the applications over time at both the individual and aggregate demand levels, this chapter discusses essential methodological issues related to SEM as it applies to tourism demand modeling. Based on this analysis, the discussion identifies the best SEM methodological practices that serve as directives when testing the various tourism 240 demand models proposed in the remaining three chapters of the dissertation.

\section{Abstract of chapter two}

Title: Modeling a Causality Network for Tourism Development: An Empirical Analysis

This paper uses the best SEM practices (as identified in Chapter 1) to propose and test measurement and structural models in AMOS 16.0 to capture the causal relationships between the constituents of the tourism destination paradigm (i.e., the economy, society, and natural and infrastructural environments) and demand for tourism at that destination. The results indicate that, although the economy construct has no direct influence on tourism, it has a mediating, positive impact on tourism through the society and environment constructs, with the society construct paralleling the condition of the infrastructure. Moreover, the society and environment were found to have a direct, positive impact on generating tourism activities and revenues. This study contributes to existing literature on tourism demand modeling by verifying causal relationships between tourism constructs and supply variables at the country level. It thus provides destination managers with a framework for understanding which variables can effectively develop a country's tourism industry.

\section{Abstract of chapter three}

Title: Extending a Causality Network Model for Tourism Development: A cross-country, multigroup empirical analysis

Chapter 3 reconsiders the a priori validated structural model for relationships among the economy, society, environment, and tourism constructs, as identified in Chapter 2, to examine the extent to which the model was invariant (or variant as previous tourism literature has suggested) across two groups of isolated observations: developed and lessdeveloped countries. The a priori model did not replicate across both groups; instead, a reduced model (including only society, environment, and tourism constructs) was used to compare and test for variances in 
parameters across the two groups using multigroup analysis sampling in AMOS 16.0. The results indicated that path coefficients were equal across groups. A positive relationship existed between society and environment constructs, while a similar positive significant relationship existed between society and environment constructs from one side and tourism, respectively.

\section{Abstract of chapter four}

Title: Examining the Effect of Novelty Seeking, Satisfaction, and Destination Image on Tourists' Return Pattern: A two-factor, nonlinear latent growth model
In contrast to the previous two chapters, which followed a supply-side perspective to analyze tourism demand, Chapter 4 explored individual differences in revisit choice over time using a latent growth curve to model the developmental trajectory of return behavior. The proposed model was tested in two steps in AMOS 16.0 using SEM methodologies to investigate the effects of novelty-seeking, destination image, and overall satisfaction levels across intent-torevisit trajectories using data collected among French, English, and German travelers. Findings indicate that novelty-seeking and low satisfaction among travelers temper immediate intent to return. Conversely, a positive image of the destination enhances both immediate and future intentions to return. 